\title{
Homeopathy and COVID-19 Pandemic in India
}

\author{
Abhijit Dutta* and Shubhamoy Ghosh ${ }^{2}$ \\ ${ }^{1}$ Office of Medical Research \& Data Management, Sanjiban Hospital, Howrah, West Bengal, India \\ ${ }^{2}$ Department of Pathology \& Microbiology, DN De Homoeopathic Medical College \& Hospital, Kolkata, West Bengal, India
}

*Corresponding Author:

\author{
Abhijit Dutta \\ Office of Medical Research \& Data Management \\ Sanjiban Hospital, Howrah, West Bengal, India \\ Contact no: +91-8240391784 \\ E-mail: drabhijitdutta1@gmail.com
}

In the past few months, the Coronavirus infection (COVID-19/ SARS-CoV-2) has invaded the globe with its infectious nature. The adverse situation and panic resulting from it has put the whole medical fraternity in a state of worry. Every country has engaged itself to fight with this deadly situation. History has rarely seen such rapidity in the development of therapies for any epidemic. Starting from Hydroxychloroquin, Remdesivir to Plasma therapy, or many of the opinion-based (or supported by weak/empirical evidence) therapies have been used. However, vaccines and effective drugs are still underway in its development, which is inevitably a time-consuming process as it involves pre-clinical to clinical translation.

In this situation, homeopathy may be an option to consider. Previously in many epidemics, it was found to be effective, even with mass intervention ${ }^{1}$. Homeopathy has an advantage due to its symptom-based approach, which is supported by some cardinal principles ${ }^{2}$.

This situation demands better therapeutic modalities. With the spread of the virus, many of the homeopathic authoritative bodies/organisations have suggested or advised the way of using homeopathic medicines in this situation. India is a country with the largest number of homeopathic physicians, institutions and users. Like many other countries, Indian homeopathic community also sought to have the opportunity to fight against this situation. Ministry of AYUSH (Ayurveda, Yoga \& Naturopathy, Unani, Siddha and Homoeopathy) under Government of India released an advisory of using homeopathic medicine Arsenicum album 30, even before the outbreak of COVID-19 in the country ${ }^{3}$. This report was criticised by many media houses and local authorities. Wikipedia also listed Homeopathy as one of the 'unproven methods for COVID-19'. ${ }^{4}$ However, these criticisms cannot stand because it was not a 'claim' by Ministry rather only an 'advisory' based on expert consensus and empiric evidence. We recall ILI during the influenza pandemic of India in 2009, where Arsenicum album was also the most indicated medicine ${ }^{5}$. The underlying symptomatology of the COVID-19 infected cases has significant similarities with Arsenicum album.
On March 28, Honourable Prime Minister of India also conducted a meeting regarding how the AYUSH workforce could be used in this situation ${ }^{6}$. In the past few months, many parts of the country were provided homoeopathic medicines as a preventive measure. Different states like West Bengal, Kerala, and other few states have adopted this policy for active interference in the community. In some of the institutions, homeopathy is also used for treating active cases. For the reason of rapidity and ethical issues, no trials with methodological rigour have been published till now, but the administrative decision in delivering homeopathy was commendable.

In the Clinical Trial Registry- India (http://ctri.nic.in/), about 14 trials are already registered till date and the number is likely to increase. On April 21, Extramural Research (EMR) section of AYUSH Ministry issued a notification to support short-term research projects for evaluating the impact of AYUSH interventions/medicines for the prophylaxis and clinical management of COVID-19, which many institutions/ organisations are likely to proceed to collaborate. We are very hopeful that within a short period of time, we will soon have results of several trials pertaining to the prevention and treatment of COVID-19.

It is high time that the homeopathic fraternity becomes active for generating evidence to help our health care system to continue caring for all patients and population. Like many other countries, Homeopathy in India is also facing various obstacles. In future, we hope to generate considerable amount of evidence from active intervention of homeopathy to combat this situation.

\section{References}

1. Jacobs J. Homeopathic Prevention and Management of Epidemic Diseases. Homeopathy. 2018 Aug;107(3):157-60.

2. Hahnemann S. Organon of medicine. 5th ed. New Delhi: B Jain Publishers; book reference system 2010.

3. Advisory for Corona virus [Internet]. [cited 2020 Jul 6]. Available from: pib.gov.in/Pressreleaseshare.aspx?PRID=1600895

4. List of unproven methods against COVID-19. In: Wikipedia [Internet]. 2020 [cited 2020 Jul 6]. Available from: https://en.wikipedia.org/w/ 
index.php?title=List_of unproven_methods_against_COVID-19\&oldid $=958132000$

5. Mathie RT, Baitson ES, Frye J, Nayak C, Manchanda RK, Fisher P. Homeopathic treatment of patients with influenza-like illness during the 2009A/H1N1 influenza pandemic in India. Homeopathy. 2013 Jul;102(3):187-92. PM interacts with AYUSH practitioners [Internet]. www.narendramodi.
in. [cited 2020 Jul 6]. Available from: https://www.narendramodi.
in/prime-minister-narendra-modi-interacts-with-ayush-practitioners-549011

doi: $10.38205 /$ imcr.020236 